\title{
APROXIMAÇÕES ENTRE O CONCEITO DE UMWELT EM UEXKÜLL E A NOÇÃO DE AMBIENTE EM BRONFENBRENNER
}

Dalízia Amaral Cruz.

Doutoranda no Programa de Teoria e Pesquisa do Comportamento UFPA. Mestre em Teoria e Pesquisa do Comportamento pelo Programa de Pós-Graduação em Pesquisa e Teoria do Comportamento - UFPA, Especialista em Psicopedagogia Institucional pela Universidade da Amazônia.

Fernando Augusto Ramos Pontes

Professor no Programa de Pós-graduação em Teoria e Pesquisa do Comportamento - UFPA. Pós-doutor pela Universidade de Brasíl e pela Technischen Universität Dortmund - Alemanha. Mestre em Teoria e Pesquisa do Comportamento pela Universidade Federal do Pará. E-mail: farp1304@gmail.com

Professora da Faculdade de Serviço Social da Universidade Federal do Pará. Credenciada como professor orientador ao Programa de PósGraduação em Teoria e Pesquisa do Comportamento, área de concentração da Ecoetologia. Mestre em Serviço Social e Doutora pelo Programa de Pós-Graduação em Teoria e Pesquisa do Comportamento da Universidade Federal do Pará, com PósDoutorado pelo Programa de Pós-Graduação em Psicologia da Universidade Federal do Rio Grande do Sul. E-mail: liliaccavalcante@gmail.com

\section{RESUMO}

O presente ensaio discute as aproximações do conceito de Umwelt, de Jakob von Uexküll e a concepção fenomenológica do meio ambiente em Urie Bronfenbrenner. Apesar de temporalmente distantes e advindos de matrizes teóricas diferentes, identifica-se vínculos epistemológicos equivalentes, visto que postulam elementos a respeito das relações entre organismos e o seu mundo externo circundante. O conceito de Umwelt de Uexküll trata mais de fenômenos na ordem dos determinantes filogenéticos, enquanto que o conceito de ambiente de Bronfenbrenner está mais direcionado para entender as determinações no âmbito da ontogênese. Contudo, os dois conceitos se aproximam por serem concepções epistemológicas no âmbito da ecologia, ou seja, da determinação das percepções e ações a partir da relação existente entre organismomeio ambiente.

PALAVRAS CHAVE: Umwelt. Meio ambiente. Ecologia. Perspectiva sistêmica. 


\title{
APPROACHES BETWEEN THE UMWELT CONCEPT IN UEXKÜLL AND THE ENVIRONMENTAL CONCEPT IN BRONFENBRENNER
}

\begin{abstract}
This essay discusses the approaches of the concept of Umwelt of Jakob von Uexküll and the phenomenological concept of the environment in Urie Bronfenbrenner. Although temporally distant and come from different theoretical frameworks, we founded equivalent epistemological bonds, as postulated about the relationship between organisms and their surrounding external world. The concept of Umwelt of Uexküll treat more phenomena in the order of phylogenetic determinants and concept of Bronfenbrenner environment is more directed to understanding the determinations under the ontogenesis. However, both share epistemological concepts in the context of ecology, that is, determining the perceptions and actions from the relationship between organism and environment.
\end{abstract}

KEYWORDS: Umwelt. Environment. Ecology. Systemic perspective.

\section{INTRODUÇÃO}

O presente ensaio pretende fazer reflexões acerca do conceito de Umwelt, de Jakob von Uexküll (1864-1944) e a concepção fenomenológica do meio ambiente em Urie Bronfenbrenner (1917-2005), visando sinalizar aproximações na maneira pela qual esses dois teóricos conceberam a relação estabelecida entre os seres humanos e o ambiente. Apesar de temporalmente distantes e advindos de matrizes teóricas diferentes, entende-se que se pode identificar vínculos epistemológicos equivalentes, visto que postulam a respeito das relações entre organismos e o seu mundo externo circundante. Uma discussão da aproximação sobre esses vínculos pode contribuir para a discussão de abordagens ecológicas, transdisciplinares e por consequente mais complexas.

A discussão das relações entre o conceito de Umwelt e uma perspectiva bioecológica pode ser posta inicialmente em torno de um referencial do paradigma sistêmico, uma matriz de encontro.

O paradigma sistêmico "representou uma profunda revolução na história do pensamento científico ocidental" (CAPRA, 1996, p. 31), possibilitou a visão de organismos vivos enquanto totalidades integrantes. Ao contrário do paradigma cartesiano, onde em todo sistema complexo, o comportamento do todo é entendido a partir das propriedades de suas partes, com reduções 
contínuas e descontextualizadas, o pensamento sistêmico é contextual, em que o organismo compõe um sistema maior, que é o seu também chamado ambiente (UHLMANN, 2002).

É nessa perspectiva de inter-relação entre todo e parte que a discussão referente ao conceito de Umwelt e de percepção do ambiente no modelo bioecológico encontra espaço de discussão. Assim, quais os condicionantes de cada relação entre unidades do sistema? Como conceber uma relação que supere a unidirecionalidade entre organismo-meio ambiente, como a presente no modelo padrão das ciências sociais e ou do modelo de endereço social? Como solucionar o dilema da relação, de modo que o foco esteja na relação? São essas algumas das questões intrigantes que perpassam pelas soluções propostas nas duas abordagens.

\section{JAKOB VON UEXKÜLL: “ALLE WIRKLICHKEIT IST SUBJECTIVE ERSCHEINUNG ${ }^{1}$ "}

Biólogo e filósofo, Uexküll é originário da nobreza Báltica é sem dúvida, um dos mais frutíferos pensadores do século XX (UHLMANN, 2002). Iniciou seus estudos biológicos em 1884 na Estônia, na Universidade de Dorpat, posteriormente “Tártu Ülikool”. Depois de formar-se, prosseguiu com seus estudos sobre fisiologia na Universidade de Heidelberg na Alemanha, atualmente "Ruprecht-Karls-Universität Heidelberg", sob a orientação do biólogo Wilhelm Kühne (1837-1900). Em seguida, mudou-se para a Universidade de Nápoles, na Itália, hoje "Università degli Studi di Napoli Frederico II", onde aprofundou seus conhecimentos sobre zoologia. Em 1907 retorna para Heidelberg e recebe o título de Doutor Honoris Causa, por suas pesquisas sobre o comportamento fisiológico muscular, com base nas quais ele começou a ensaiar uma "lei da Umwelt" (ARAÚJO, 2004).

Em 1927, Uexküll inaugura o Instituto de Pesquisa da Umwelt - Institüt für Umweltensforschung, na Universidade de Hamburg (Universität Hamburg) na Alemanha, onde publicou a segunda edição de sua obra "Biologia Teórica" -Theoretische Biologie - em 1928. Nesse livro, Uexküll vai além de uma biologia restrita a descrições sobre estruturas anatômicas, atentando, notadamente, para as subjetividades dos seres vivos, bem como do ser humano, sendo observador-pesquisador. Com a elaboração da obra "Teoria da Significação", em 1940, Uexküll foi reconhecido como o pai da Biossemiótica e precursor da Biocibernética.

${ }^{1}$ Toda realidade é um fenômeno subjetivo. 
Central em seu modelo e reconhecidamente a sua mais importante contribuição teórica é a noção de Umwelt. No livro "Umwelt und Innenwelt der Tiere", Uexküll (1909) introduziu o termo Umwelt para denotar o mundo subjetivo do organismo. Para nos aproximarmos do conceito de Umwelt, deve-se evitar uma tradução literal. A despeito que o termo em alemão tenha uma tradução direta para o português de "meio ambiente", como assinala a nota de tradução presente em Uexküll

(1982, p. 24), no contexto da sua teoria, "este conceito significa qualquer coisa que depende do ser vivo, em virtude de sua própria estrutura específica - o seu mundo próprio”. Deste modo, a noção de mundo próprio parece ser a mais apropriada para o português.

Apreende-se da Umwelt como sendo a interface filtrante, que patrocina a seletividade da percepção, a qual foi impressa em cada espécie vivente por meio do processo evolutivo de permanência no mundo. É a mediação das decisões operacionais de conduta de cada ser vivo, conforme seus interesses de sobrevivência, como um diálogo reativo às ocorrências fenomênicas de seu correspondente habitat. Segundo Uhlmann (2002, p. 55), "as espécies exploram a relação espaço e tempo tendo uma interação que varia de espécie para espécie em função das exigências do próprio ambiente".

A pergunta que Uexküll se fazia era, como é o mundo para uma borboleta? Como é o mundo para uma determinada espécie de pássaro? Como um exemplo da abordagem dessa questão, há o exemplo clássico do carrapato explorado por Uexküll. Os carrapatos são pequenos artrópodes da ordem dos ácaros, da família Ixodidae ou Argasidae. São ectoparasitas hematófagos, ou seja, se fixam em organismos de sangue quente para se alimentar. Apesar de viverem sem alimento por muitos meses, necessitam de sangue para gerar ovos fecundados. Na sua sina em busca de alimentação o carrapato aguarda, em um galho a passagem de sua presa.

Com a passagem de um animal com sangue, suas pernas abrem-se e o inseto deixa-se cair entre os pelos de um mamífero, em seguida passa a sugar o sangue do animal. Uexküll acreditava que não, pelo menos da forma que nos humanos, entendemos estes estímulos.

Carrapatos são cegos e surdos, possuem apenas três receptores (“órgãos perceptivos”), que podem captar três diferentes "signos perceptivos" (perceptual signs [Merkzeichen]): (1) signos olfativos causados pelo ácido butírico, que pode ser encontrado no suor de todos os organismos de sangue quente; (2) signos táteis como o induzido pelo couro peludo dos mamíferos e (3) signos temperaturais produzidos pelo calor das áreas dérmicas lisas. Cada signo 
se refere a uma resposta específica iniciada pelo signo. Deste modo, não é visão de um animal que desencadeia o salto e sim uma coluna de cheiro. Pode-se dizer que o carrapato faz um verdadeiro salto no ar, no seu salto coincidentemente cai na fonte de cheiro, neste caso um animal. Após cair em um animal suga o líquido que esteja em uma temperatura de um animal de sangue quente, o carrapato não suga o sangue, mas sim qualquer líquido independente de sabor e consistência.

O exemplo do carrapato nos leva a pensar que a representação interna que o organismo faz de seu Umwelt não é o mesmo que o Umwelt em si. Em outras palavras, as informações da realidade, acessáveis pelos seus órgãos dos sentidos. Dessa forma, a representação interna do Umwelt é denominada por Uexküll de Innenwelt. Ou seja, o meio ambiente (Umwelt) é descrito do ponto de vista interno (Innenwelt) das espécies. Se constitui pelo "mundo de percepção" e "mundo de ação" de um organismo, que cria ou interpreta o meio a partir de um modo subjetivo. Nesse sentido, o que é significativo no mundo próprio de um organismo é o que tem influência em sua ação no meio. Veja-se, portanto, que a significação implica ação no mundo. Os objetos têm função enquanto significa algo útil ou biologicamente relevante no interior de um mundo próprio (ARAÚJO, 2012).

Em síntese, Uexküll designa como "mundo-próprio" os modos particulares de "percepção" e "ação" de um organismo em função do conteúdo perceptivo da experiência. Nas palavras de Uexküll (1934, p.25), “[...] tudo aquilo que um sujeito assinala passa a ser seu mundo-depercepção, e o que ele realiza, seu mundo-de-ação. Mundo-de-percepção e mundode-ação constituem uma unidade íntegra - o mundo-próprio do sujeito" De acordo com Araújo (2004), para

Uexküll o é essencial no trabalho do biólogo é capturar a atividade de significação, que é parte do "mundo-próprio" do organismo, como expressão de um "sujeito" ou "subjetividade" que está inscrita na própria estrutura física ou corpo do organismo.

A despeito que toda reação poderia ser interpretada como um simples comportamento reflexo em cadeia, visto que tudo funciona como peças conectadas que conduzem ondas excitatórias de simples resposta ao meio ambiente. Contudo, o que ressalta a noção de Umwelt é que os estímulos precisam ser notados e distintos do conjunto do meio por um sujeito, assumindo a função de um sinal (ARAÚJO, 2004). Logo o comportamento não pode ser tomado 
como uma simples reação ao meio externo, visto que o sinal (ácido butírico e temperatura do liquido) deve ser organizado pelas células de percepção.

Como destaca Uexküll (1934):

Todas as nossas sensações humanas, que figuram os nossos assinalamentos, ou percepções, específicos, convergem nos atributos dos objetos exteriores que nos servem como sinais-característicos que utilizamos. A sensação "azul" passa a ser a "cor azul" do céu; a sensação "verde" passa a ser a "cor verde" da relva, etc. No sinal característico, ou carácter azul, reconhecemos o céu, no carácter verde reconhecemos a relva.

Assegurando-se na noção de Umwelt que diferentes organismos, dos mais simples aos mais complexos, estão ajustados (para não dizer acoplados) aos seus respectivos mundospróprios, diferentes funções e significados dependerão da história evolutiva da espécie em questão. Contemporaneamente, essas noções estão ligadas ao conceito de sistemas autorreferentes (MATURANA; VARELA, 1980, 1997), os quais concebem um sistema vivo como sistema autônomo, as mudanças possíveis em um sistema vivo são controladas e limitadas por sua própria estrutura, ou seja, sistemas estruturalmente determinados são tais que, qualquer agente externo, agindo sobre eles, apenas dispara neles mudanças estruturais determinadas por sua própria estrutura.

A noção de Umwelt de Uexküll foi adequadamente apropriada especialmente pela etologia para se referir às predisposições e preferências inatas. Neste sentido, a noção de Umwelt refere-se às determinações biológicas dadas no decorrer da filogênese. Evidentemente, que posteriormente para a própria etologia, a noção de repertório inato como imune à aprendizagem faz pouco sentido, visto não haver nenhum comportamento imune a experiência. Contudo, as predisposições de percepções e ações podem ser interpretadas como decorrentes da história evolutiva de cada espécie e, por este motivo faz mais referência à filogênese do que a ontogênese.

\section{URIE BRONFENBRENNER: "DESENVOLVIMENTO (...) MUDANÇA DURADOURA NA MANEIRA PELA QUAL UMA PESSOA PERCEBE E LIDA COM SEU AMBIENTE"}

Nascido em Moscou - Rússia em 1917. Quando ele tinha seis anos, sua família se mudou para os Estados Unidos. O seu pai trabalhava como neuropatologista em uma instituição estadual que cuidava de pessoas com problemas mentais. Cresceu nesta instituição e vivenciou 
experiências que influenciaram a sua concepção ecológica desenvolvida posteriormente, principalmente quanto aos aspectos biológicos e sociais.

Tornou-se Ph.D. pela Universidade de Michigan em 1942. Atuou, nesta mesma Universidade como professor assistente em Psicologia. Em 1948, aceitou um cargo de professor em Desenvolvimento Humano, Estudos da Família e Psicologia da Universidade de Cornell.

Os conhecimentos compartilhados com o pai, bem como o ambiente em que viveu sua infância, foram, de acordo com Bronfenbrenner, o campo biológico e social que influenciaram o seu pensamento. Bronfenbrenner desde cedo considerou a interdependência entre os organismos vivos e seu ambiente (NARVAZ; KOLLER, 2004). Veja-se que a pessoa e o ambiente se influenciam mutuamente, a pessoa não se desenvolve, somente, a partir de influências do contexto, ela também exerce sua influência em prol de seu próprio desenvolvimento.

Interessado sobre o desenvolvimento humano desenvolveu criticou a tradicional psicologia do desenvolvimento baseado seja por um lado no estudo das diferenças individuais e por outro na generalização do desenvolvimento com base em referenciais do contexto sócio económico cultural, o que ele chamava de modelo padrão das ciências sociais, entender o desenvolvimento com base no endereço social. Segundo Bronfenbrenner (1996), psicologia do desenvolvimento foi a ciência do comportamento estranho de crianças em situações estranhas a elas e com adultos também estranhos por breves períodos de tempo.

Em sua teoria do desenvolvimento, concebe diferentes níveis de influências ambientais sobre o desenvolvimento, devido seus contatos com processos proximais em diferentes sistemas encaixados (-micro, -meso, -exo e macrossistema). Mais tarde, ele acrescentou a dimensão tempo a esses sistemas (cronosistema). Posteriormente, este modelo foi denominado de bioecológico, por reconhecer a importância de processos biológicos em desenvolvimento. $\mathrm{O}$ prefixo "bio" foi entendido principalmente como uma característica da dimensão pessoa.

Ao estruturar a abordagem bioecológica do desenvolvimento humano, em 1970, influenciado pelas concepções de Dilthey, George Mead e principalmente Kurt Lewin, Bronfenbrenner reorienta a concepção da psicologia tradicional, a qual reduz as funções psicológicas, dando aos processos psicológicos uma conotação individualista/intimista. Deste modo, na sua teoria bioecológica compreende os processos psicológicos como propriedades de sistemas, tendo a pessoa como um dos elementos. No entanto, Bronfenbrenner, no início da 
teoria, ao dá ênfase aos aspectos dinâmicos do contexto, acaba deixando os aspectos da pessoa um tanto quanto secundarizados. De acordo com ele, seu estudo careceu de um "conjunto de estruturas que conceitualizassem as características do desenvolvimento da pessoa" (BRONFENBRENNER, 1989, p. 188). Por isso, em seu modelo teórico bioecológico (BRONFENBRENNER; MORRIS, 1998; BRONFENBRENNER; $\quad$ CECI, 1994;

BRONFENBRENNER; EVANS, 2000), Bronfenbrenner inclui os níveis estrutural e funcional do indivíduo, articulando-os de forma dinâmica com os sistemas ecológicos (-micro, -meso, -exo e macrossistema). O acréscimo do prefixo "bio" ao ecológico já demarca sua preocupação com a influência das características (biológicas, psicológicas e comportamentais) da pessoa para o próprio desenvolvimento. E é nesse sentido que faz uma autocrítica às suas proposições iniciais, revisando e ampliando seus principais conceitos, nos apresentando, portanto, o modelo teórico bioecológico, por meio de quatro núcleos inter-relacionados: o chamado PPCT (Processo, Pessoa, Contexto e Tempo).

No modelo bioecológico é dado um destaque para concepção do ambiente, o ambiente de desenvolvimento não concebido em função de características apriorísticas alheias a características da pessoa, tal como as características do ambiente físico e social, o importante a ser descrito do ambiente é como a pessoa o percebe. Não há pois um ambiente independente do indivíduo, ele é que lhe dá sentido e por sua vez reage aos sentidos por ele dado.

A importância desta compreensão é tão marcante para o modelo, que Bronfenbrenner (1996) desenvolve o conceito metodológico de "validade ecológica" como uma forma de avaliar a correspondência do ambiente do observador e do observado. A validade ecológica consiste então na extensão pela qual a pessoa em desenvolvimento experiência o seu ambiente, considerando as propriedades ou condições especifícas resultantes das hipóteses levantadas pelo pesquisador, em uma investigação científica. Deste modo o conceito de validade ecológica tem implicações em alguns preceitos importantes para o planejamento e a realização da pesquisa, a partir do momento que considera como a pessoa em desenvolvimento percebe a si própria na situação, interagindo com as condições presumidas ou desejadas pelo pesquisador.

O modelo bioecológico de Bronfenbrenner é um modelo que trata da ontogênese e concebe por sua vez o desenvolvimento ontogenético de acordo com a ecologia de cada sujeito. No decorrer do desenvolvimento, mais importante do que destacar as variáveis sócio demográficas de cada sujeito, seu endereço social, está em destacar como ele percebe seu 
entorno proximal e distal, sua ecologia, variáveis como estresse, resiliência, rede de suporte não são definidas alheias ao sujeito, mas a partir do próprio sujeito, de sua percepção.

\section{UEXKÜLL E BRONFENBRENNER: APROXIMAÇÕES ENTRE A BIOSSEMIÓTICA E A BIOECOLOGIA}

O termo Umwelt, apresentado por Uexküll em 1909, ganha uma concepção sócio psicológica em que ambiente se relaciona a um organismo que interage e age de acordo com a estrutura e estado do seu mundo interno. Em termos literais, trata-se do "mundo ao redor". Se pensarmos no âmbito humano, o ambiente configura-se enquanto o entorno, que de forma subjetiva, é significativo para um indivíduo ou grupo. Assim, as pessoas e grupo de pessoas experienciam, ao longo da vida, conjuntos de significados, denominados Umwelten. Em outras palavras, Umwelt se define como algo que tem um efeito real ou potencial sobre uma pessoa ou grupo; pode ser um aspecto percebido abertamente e sensorialmente ou até mesmo, influências sutis ou como espaço de ação (KRUSE, 2005).

A máxima de Uexküll que "toda realidade é um fenômeno subjetivo" se articula ao que Koller (2011, p.15) diz ser o núcleo central da teoria de Bronfenbrenner, em que o estudo do desenvolvimento humano deve estar centrado na "observação naturalística de seres humanos reais, nos seus ambientes reais, interagindo com outros seres humanos, objetos e símbolos também reais, ainda que fossem para eles".

Do ponto de vista fenomenológico, tanto a Biologia de Uexküll quanto Bioecologia do Desenvolvimento de Bronfenbrenner, os fenômenos são interpretados a partir da percepção de quem experiência determinado fenômeno. No caso da noção de Umwelt, determinado a partir da história evolucionária de determinada espécie e no modelo bioecológico, na história ontogenética do indivíduo, por exemplo, na experiência arraigada nas crenças e valores da pessoa, o que está intimamente relacionado à subjetividade de cada um.

Conforme Bronfenbrenner (2011), "experiência” é um termo chave, uma vez que as características relevantes de qualquer contexto - conjunto de condições ambientais - para o desenvolvimento humano abarcam tanto as condições objetivas, quanto as subjetivas, ou seja, a maneira pela qual essas condições são experienciadas subjetivamente pelas pessoas que vivem e agem no ambiente.

Em cada ambiente, a pessoa, que atua ativamente, faz um recorte da realidade a partir das percepções e das propriedades que têm significado para ela e, por isso, importância para sua 
existência (UHLMANN, 2002). A exemplo, Uexküll apresenta as propriedades do Carvalho (árvore), percebidas subjetivamente de forma diferente pelo guarda florestal ou por crianças, conforme suas experiências e significados atribuídos. Uexküll exemplifica da seguinte maneira: para um guarda florestal, que irá determinar as árvores prontas para o corte, na racionalidade do mundo circundante, o Carvalho representa um lote de lenha a ser medido e contabilizado. Já no caso das crianças, a floresta em que se encontra a árvore pode ser o ambiente delas. Nesse caso, a casca com formações que se assemelham em alguns aspectos a uma feição humana ganha destaque de observação. De modo semelhante, uma jovem menina, pode apreender o mundo como encantado/mágico. A floresta, então, passa a ser habitada por gnomos e duendes, a menina se assusta com as feições horrendas do carvalho, de modo que a árvore é percebida como uma entidade monstruosa.

Para falar da importância fenomenológica do meio ambiente, Bronfenbrenner (2011), explicitamente influenciado pelas ideias de Kurt Lewin, especialmente pelo constructo do "espaço de vida" ou "campo psicológico", cita o artigo de Lewin "Paisagem de guerra" (Kriegslandschaft). Este artigo foi publicado no final da Primeira Guerra Mundial e, nele, Lewin descreve como a realidade percebida da paisagem se modifica, conforme a pessoa se aproxima da frente de combate:

O que a princípio parece uma adorável cena bucólica de casas de fazenda, campos e bosques é gradualmente transformado. O topo da colina arborizada se transforma num posto de observação, seu lado protegido, o lugar em que estarão as armas. Uma clareira abrigada é vista como uma provável estação de socorro para o batalhão. Aspectos da paisagem natural que eram uma delícia a apenas alguns quilômetros de distância agora são percebidos como sinistros: o desfiladeiro assustador, a camuflagem das árvores, a colina que esconde o inimigo oculto, o objetivo invisível a ser atingido, o lugar e o momento da segurança depois da luta - aspetos do ambiente que ameaçam, dirigem, reasseguram e orientam o curso da pessoa através de um terreno objetivamente indistinguível de cenas a uma curta distância da frente de batalha (BRONFENBRENNER, 1996, p. 20).

Elementos objetivos e subjetivos, com igual relevância, dirigem o percurso desenvolvimental humano. A força fenomenológica e experiencial aplica-se em esferas distintas. O primeiro é mais frequentemente relacionado ao ambiente objetivo, formados por representações subjetivas. É o que se sente/sabe do ambiente. Agora, o que se faz/sente em relação ao ambiente é experiencial. 
Tanto Bronfenbrenner, quanto Uexküll chamam a atenção para a importância do ambiente fenomenológico, contudo um destaca mais pela perspectiva dos determinantes filogenéticos e outro pelos ontogenéticos. A mensagem comum, o ponto de encontro dos dois constructos dos dois autores é que não se pode compreender o comportamento somente a partir das propriedades objetivas do ambiente. Faz-se necessário voltar-se ao significado semiótico dos ambientes em que vivem, pois o ambiente não é o que é, mas o que ele representa. Nos organismos mais simples há sempre uma parcela de recorte do ambiente e nos mais complexos, uma representação simbólicas, nos dois casos, não são o que são mais o que significam.

Neste caso, o irreal e o imaginado têm especial importância. O desenvolvimento do mundo da fantasia da criança aponta o fato de que suas percepções e atividades que emergem não são apenas reflexo do que é percebido, há um aspecto ativo e criativo (BRONFENBRENNER, 2011). Para Uexküll (1982), a partir dos mundos próprios, surgem aspectos de grande eficácia, no entanto, só são percebidos pelo sujeito que estão relacionados com acontecimentos excepcionais, os chamados mundos-imaginários.

\section{CONSIDERAÇÕES FINAIS}

De acordo com Thure von Uexküll (2004), filho de von Uexküll, a premissa epistemológica do pai é "sistêmica", uma vez que para ele o processo vital era concebido como um sistema coerente, onde sujeito e objeto se definem como elementos inter-relacionados em um todo maior. Aliás, a conceituação do objeto por Uexküll antecipa a de "sistema aberto", o qual interage com seu meio ambiente, indo de encontro a conceituação sistema fechado. Cada processo de observação pressupõe interações entre o observador e o sistema observado. Desse modo, é impossível examinar objetos isolados de seu ambiente.

Nesta perspectiva, Bronfenbrenner (1996, p. 5), considera o ambiente ecológico "como uma série de estruturas encaixadas, uma dentro da outra, como um conjunto de bonecas russas". O nível mais interno corresponde ao ambiente imediato da pessoa em desenvolvimento, o microssistema, dentro do qual ocorrem os chamados Processos Proximais, caracterizados por um padrão de atividades, papeis e relações interpessoais, experienciados pela pessoa desenvolvente. São processos específicos de interação entre a pessoa em desenvolvimento e o contexto que se estabelecem no decorrer do tempo (BRONFENBRENNER; MORRIS, 1998). 
No próximo nível, tem-se o mesossistema, configurado a partir das inter-relações entre dois ou mais microssistemas, em que a pessoa participa ativamente. No que tange à pessoa, esta traz para as suas situações sociais características de demanda, recurso e força (TUDGE, 2008). O terceiro nível abrange os ambientes em que a pessoa não atua ativamente, mas no qual ocorrem eventos que afetam e/ou são afetados por eventos que ocorrem no ambiente imediato da pessoa em desenvolvimento. E por fim, o quarto nível, macrossistema, que "consiste no padrão global de características do micro, meso e exossistema de determinada cultura, subcultura ou contexto social mais amplo" (BRONFENBRENNER, 2011, p. 177).

Os enunciados apresentados pelos biólogos organísmicos ao longo da primeira metade do século XX contribuíram para o surgimento de um novo modo de pensar em termos de conexidade, de relações, de contexto. Para o pensamento sistêmico, as propriedades primordiais de um organismo, ou sistema vivo, são propriedades do todo, onde nenhuma das partes possui, surgem das interações e das relações entre as partes (CAPRA, 1996).

A visão da realidade, enquanto rede indissociável de relações, diz respeito à concepção tradicional de objetividade científica. O ponto de vista científico cartesiano considera as descrições objetivas, ou seja, independem do observador humano e do processo de conhecimento. Na contramão, para o paradigma sistêmico, a compreensão do processo de conhecimento deve ser incluída na descrição dos fenômenos naturais. É arbitrário isolar um padrão em uma rede complexa, criando uma fronteira ao seu redor e chamar esse padrão de "objeto" (CAPRA, 1996). No pensamento sistêmico, a natureza é compreendida como uma teia interconexa de relações, onde a identificação de padrões específicos como sendo "objetos" vai depender do observador humano e do processo de conhecimento.

No âmbito do pensamento sistêmico, o indivíduo/organismo vivo percebe as suas alterações, bem como as dos contextos, a partir da sua ótica e significado atribuído a essas alterações. Em outras palavras, segundo sua percepção, a pessoa torna-se capaz de interagir em diferentes e diversos contextos, restaurando-os e suplantando as limitações que o meio impõe. Neste sentido, a noção de Umwelt em Uexküll e de ambiente em Bronfenbrenner compartilham a perspectiva de serem ecológicas, pois o que determina a percepção, e consequente ação, é a relação que os organismos têm com seus ambientes, sejam estes amebas ou pessoas. 


\section{REFERÊNCIAS}

ARAÚJO, A. O. de M. Significação sem representação: a teoria pragmática da significação de Jakob von Uexküll. Ciências \& Cognição, v. 17, n. 2, p. 98-114, 2012.

ARAÚJO, E. F. A teoria da Umwelt de Jakob von Uexküll: apresentação. Galáxia, v. 4, n. 7, 2007.

BRONFENBRENNER, U. A ecologia do desenvolvimento humano. Porto Alegre: Artes Médicas, 1996.

- Biologia do desenvolvimento humano: tornando os seres humanos mais humanos. Porto Alegre: Artes Médicas, 2011.

U.; MORRIS, P. The ecology of developmental processes. In R. M. Lerner \&W. Damon (Org.), Handbook of child psychology. New York: John Wiley \& Sons. p. 993-1027. 1988.

U.; EVANS, G. Developmental Science in the 21st century: emerging questions, theoretical models, research designs and empirical findings. Social Development, v.9, n.1. p.115125, 2000.

. U.; CECI, S. J. Nature-nature reconceptualized in developmental perspective: A bioecological model. Psychological Review, v.10 n.4. p. 568-586, 1994.

CAPRA, F. A Teia da Vida. São Paulo: Cultrix, 1996.

KRUSE, Lenelis. Compreendendo o ambiente em Psicologia Ambiental. Psicologia Usp, v. 16, n. 12, p. 41-46, 2005.
MATURANA. H; VARELA. F. Autoposieis and cognition: the realization of the living. London: $\mathrm{D}$. Reidel Publishing Company, 1980.

. De máquinas e seres vivos - autopoiese: a organização do vivo. Porto Alegre: Artes Médicas,1997.

NARVAZ, M. G.; KOLLER, S. H. (2004). O modelo bioecológico do desenvolvimento humano.

In. S. H. Koller (Org.), Ecologia do desenvolvimento humano - pesquisa $e$ intervenção no Brasil. São Paulo: Casa do Psicólogo, 2004.

TUDGE, J. A teoria de Urie Bronfenbrenner: Uma teoria contextualista? In L. V. C. Moreira \& A. M. A. Carvalho (Orgs.), Família e educação: Olhares da psicologia. São Paulo: Paulinas. p. 209-231, 2008.

UHLMANN, Günter Wilhelm. Teoria geral dos sistemas: do atomismo ao sistemismo, uma abordagem sintética das principais vertentes contemporâneas desta proto-teoria. Centro Interdisciplinar de Semiótica da Cultura e da Mídia. São Paulo: USP, 2002.

VON UEXKÜLL, T. A teoria da Umwelt de Jakob von Uexküll. Galáxia, v. 4, n. 7, 2007.

VON UEXKÜLL, J. . Umwelt und innenwelt der tiere. Berlim: Springer, 1921.

Dos animais e dos homens. Tradução de Alberto Candeias e Aníbal Garcia Pereira. Lisboa: Livros do Brasil, 1982. Originalmente publicado em 1934. 
CRUZ, Dalízia Amaral; PONTES, Fernando Augusto Ramos; CAVALCANTE, Lília Iêda Chaves. Aproximações Entre O conceito de Umwelt em Uexküll e a noção de ambiente em Bronfenbrenner. Complexitas - Rev. Fil. Tem., Belém, v. 1, n. 1, p. 139-152, jan./jun. 2016. Disponível em:<http://www.periodicos.ufpa.br/index.php/complexitas/article/view/3416 >. Acesso em: 05 jul. 2016. 